\title{
Discrete Element Simulation on the Key Parameters of Bucket Wheel Stacker- Reclaimer Based on Virtual Prototyping Technology
}

\author{
Ruibin Han ${ }^{1, *}$ and Yuren Guo ${ }^{2}$ \\ ${ }^{1}$ Chn Energy Huanghua Port Affairs Co., Ltd, Cangzhou, 061113, China \\ ${ }^{2}$ School of Hotel and Tourism Management, Macau University of Science and Technology, Macau, 999078, China
}

Received 27 March 2020; Accepted 2 August 2021

\begin{abstract}
The key to the simulation of key parameters of bucket wheel stacker-reclaimer depends on simulating its operation via discrete element analysis software. However, neither the operating performance nor the economic benefit obtained by the existing methods can reach the optimal effect. To acquire the optimal productivity parameter of bucket wheel stackerreclaimer, a discrete element simulation model was designed for the key parameters of bucket wheel stacker-reclaimer based on virtual prototyping technology. Specifically, an LDQZ2500 bucket wheel stacker-reclaimer was chosen as the study object, and the constraint relations between its components were defined. Multiple rigid bodies and discrete flexible beam elements were used to establish a virtual prototype model for the bucket wheel stacker-reclaimer and input into EDEM software. EDEM software was employed to realize the discrete element simulation of this virtual prototype through the discrete element method, and its key parameters were determined through the simulation results. Results show that the error between the simulation result of the virtual prototype model and the actual operation result of bucket wheel stacker-reclaimer is extremely small. When the bucket capacity was $1.3 \mathrm{~m}^{3}$ and the rotational speed was $6 \mathrm{r} / \mathrm{min}$, the bucket wheel stacker-reclaimer exhibits the best operating performance and economic benefit. The key parameters acquired in this study provide a reference for the integrated design and efficient operation of bucket wheel stackerreclaimer.
\end{abstract}

Keywords: virtual prototyping technology, bucket wheel stacker-reclaimer, key parameter, discrete element simulation, EDEM software, constraint relation

\section{Introduction}

A bucket wheel stacker-reclaimer is efficient handling machinery (continuous transport) that can stack and reclaim materials in large-scale dry bulk storage yards. It is composed of an adhesive tape-like conveying arm capable of pitching and horizontal swinging, front-end bucket wheel, and rack and running gear, where the adhesive tape can operate in two directions. The materials are sent by the bucket wheel through the conveying arm in the reclaiming process, and the cargoes transported by the main conveyor are thrown to the storage yard via the conveying arm during the stacking process. A bucket wheel stacker-reclaimer is rail-type handling machinery that reclaims the materials by using the bucket wheel and continuously stacks the materials by using the on-vehicle belt conveyor. As special machinery applied to bulk material (bulk cargo) storage yards, it evolves from the bucket wheel excavator and can form a transportation mechanization system of storage yard together with car (ship) unloader, belt conveyor and car (ship) loader, with the production capacity reaching over 10,000 tons per hour. In terms of the structure, the bucket wheel stackerreclaimer is divided into arm frame type and bridge frame, where the arm frame type has two operating modes: stacking and reclaiming. For the stacking process, the bulk cargoes transported by the belt conveyor are unloaded to the belt conveyor on the arm frame through the tripper car and then thrown to the storage yard from the front end of the arm frame. The material pile can form an orderly shape with trapezoidal cross-section through the operation of complete machine and the turning and pitching of arm frame. The material reclaiming is continuously realized through the turning of arm frame and rotation of bucket wheel. The materials are unloaded to the arm frame belt conveyor, which operates inversely through the stripper plate and carried by the belt conveyor via the bucket beneath the machining center. The bucket wheel can take all materials in the storage yard by means of the operation of complete machine and the turning and pitching of arm frame. In terms of the bridging form, the bridge frame-type bucket wheel stacker-reclaimer is divided into gate type and bridge type, and some reclaimers are called bucket-wheel because they only have the reclaiming function. The operation of bucket wheel stacker-reclaimer, which is of extremely strong regularity, can be easily automated. The control mode is divided into manual, semiautomatic, and automatic modes. During the operation of bucket wheel stacker-reclaimer, large batch of bulk materials are reclaimed by virtue of the digging action of bucket wheel [1]. The bucket wheel should cooperate with equipment, such as car dumper, and its production efficiency is approximately twice of a singlebucket loading machine. The bucket wheel stacker-reclaimer, which has a wide operating range [2], applies to various places. The development of bucket wheel stacker-reclaimer in China has experienced three phases: (1) small-scale 
bucket wheel stacker-reclaimer, where the typical machine models are 3025,8030 , (2) large-scale bucket wheel stackerreclaimer, which is applied to the piling and transfer of bulk materials, with the material force output of $2,000 \mathrm{t} / \mathrm{h}$ and turning radius of 40 , and (3) turning radius-type bucket wheel stacker-reclaimer. During the working process of bucket wheel stacker-reclaimer, the interaction between materials and bucket wheel and that between materials are relatively complicated. The traditional method, which has some uncertainties, deviates considerably from reality. A virtual prototype model design of bucket wheel stackerreclaimer provides valuable reference for determining the working parameters of bucket wheel stacker-reclaimer and stabilizing its operation. It is directly related to the reclaiming effect of bucket wheel stacker-reclaimer. Thus, studying the bucket wheel stacker-reclaimer and bulk cargoes is extremely important.

Discrete element method (DEM) is an important simulation analysis method at present, and EDEM software is commonly used discrete element analysis software. In this study, a virtual prototype of bucket wheel stacker-reclaimer was established, and the material digging, lifting, and unloading process in the operation of bucket wheel stackerreclaimer was simulated through the discrete element analysis software [3-5]. Its reclaiming mechanism was discussed on the basis of the simulation results, thereby providing a theoretical basis for the optimization design of bucket wheel stacker-reclaimer and the selection of optimal parameters. The DEM method provided an effective analytical means for studying the digging process of bucket wheel stacker-reclaimer. The motion behavior of particle materials was simulated by using the DEM method to avoid substantive tests and experiments. This method helps in reducing the cost, acquiring the needed data, clarifying the essence of motion between particles [6-7], realizing the optimization design of bucket wheel stacker-reclaimer, and improving its production efficiency. The virtual prototype simulation technology uses 3D software to establish a simulation object model and realize the performance evaluation.

\section{State of the Art}

In the existing literature, the bucket wheel stacker-reclaimer and bulk materials have been deeply and extensively explored, certain research progress has been achieved. Many models related to bucket wheel stacker-reclaimer and bulk materials have been proposed, and the related technologies have developed rapidly. Clements et al. [8] conducted a simulation study of cloth material and sieving performance of cloth sieving system composed of mobile adhesive tapewide adhesive tape roll screen by using a discrete element model. However, the cost of this study is high. Araujo et al. [9] applied kinematics to the bucket wheel stacker-reclaimer and determined the working space of the mechanical cantilever. However, poor operating performance is obtained. Liu et al. [10] determined the final boundary parameters for the established discrete element model of manure particles. However, the simulation results deviate considerably from the practical operation results. Cao et al. [11] determined the values of the related physical property parameters of wet bucket-type polishing abrasive materials during the contact process. On the basis of EDEM discrete element simulation, they selected Hertz-Mindlin and JKR contact models from the system and calibrated the optimal combination of parameters in the discrete element simulation of wet buckettype abrasive particles by taking angle of repose as the evaluation index. Cheng et al. [12] presented a new contact detection method to determine the contact point and used a rolling resistance model to dissipate the rotational kinetic energy and realize the mechanical balance. They verified the effectiveness of this method through a series of tests. On the basis of the DEM, Vyazmensky et al. [13] established a geological model for the layered excavation of a thin-layer open slope. They explored and summarized its toppling deformation characteristics by combining indoor and outdoor evaluations. Sun et al. [14] studied the weight loss optimization problem of the forearm of bucket wheel stacker-reclaimer under various uncertain factors, such as structural parameters, material properties, load, and substitution model. Billah et al. [15] minimized the forearm weight of bucket wheel stacker-reclaimer while ensuring its strength, stiffness, and nonresonance. They proposed a point cloud management and visualization method by installing laser radars on a bucket-wheel stacker-reclaimer (BWR) and implemented accurate and real-time management and visualization of point cloud by using a semiautomatic system of point cloud data. Kannan et al. [16] developed a CFDDEM framework for gravity meter optimization, and found that the separation quality is very sensitive to the change of operating conditions. Although the above methods have their advantages, they have obvious limitations, such as failure to acquire the optimal working parameters of BWR, low machine operating efficiency, failure to utilize the machine. Consequently, either the operating performance or the economic benefit obtained through the simulation cannot reach the best effect. The virtual prototype model of bucket wheel stacker-reclaimer remains to be further improved, the theoretical analysis is imperfect, and the virtual prototype model design of bucket wheel stacker-reclaimer is faced with enormous challenges. Designing the optimal key parameters of bucket wheel stacker-reclaimer is still an important research direction.

A discrete element simulation model was established on the basis of virtual prototyping technology to acquire more ideal key parameters of bucket wheel stacker-reclaimer. The structural model of bucket wheel stacker-reclaimer was simplified, and a virtual prototype model was established. The optimal parameters contributing to the good operation of bucket wheel stacker-reclaimer were determined through the DEM method on the basis of the virtual prototype simulation results. EDEM software was used to simulate the reclaiming process of bucket wheel stacker-reclaimer. The angular variation is 24.95 in the material digging process, the pitching angular velocity is stabilized to $0.013 \mathrm{rad} / \mathrm{s}$, and the maximum relative wheel-pressure error between the simulation result and the experimental result is lower than $1 \%$ through the experimental verification. The proposed method can realize a good simulation of the reclaiming process of bucket wheel stacker-reclaimer. The established model can be used to realize the discrete element simulation and effectively reduce the energy consumed in the operation of bucket wheel stacker-reclaimer.

The remainder of this study is organized as follows: Section three expounds the experimental design and EDEM discrete element simulation of the key parameters of bucket wheel stacker-reclaimer. Section Four proposes a virtual prototype model and presents the result analysis. Section five summarizes the whole paper and provides the related conclusions. 


\section{Methodology}

3.1 Virtual prototype of bucket wheel stacker-reclaimer An LDQZ2500 bucket wheel stacker-reclaimer was selected as the study object to establish a virtual prototype model. The axes $\mathrm{x}$ and $\mathrm{y}$ of the established bucket wheel stackerreclaimer model are the horizontal line at the bottom of the vehicle wheel of traveling mechanism and the centerline of turning platform, including bucket wheel, driver's cage, pitching mechanism, and turning platform. The turning platform and arm frame of bucket wheel stacker-reclaimer were connected by using a hydraulic cylinder to realize the height adjustment of the upper mechanism and arm frame. The particle materials were stacked and reclaimed through the turning and movement of the established traveling mechanism in different directions.

The ground conveyer belt of bucket wheel stackerreclaimer was connected to the fixed-type tripper car structure, thereby ensuring that the machine pitching and turning motion characteristics were unaffected by the motion of complete machine. The structural model of bucket wheel stacker-reclaimer was simplified, the tripper car structure was ignored, and a virtual prototype model was constructed.

Table 1. Constraint Relations between Components

\begin{tabular}{|c|c|c|c|c|}
\hline $\begin{array}{l}\text { Constrained } \\
\text { component }\end{array}$ & $\begin{array}{l}\text { Constraint } \\
\text { part }\end{array}$ & $\begin{array}{l}\text { Constraint } \\
\text { quantity }\end{array}$ & $\begin{array}{l}\text { Degree of } \\
\text { freedom }\end{array}$ & $\begin{array}{l}\text { Setting } \\
\text { mode }\end{array}$ \\
\hline $\begin{array}{l}\text { Gate seat and } \\
\text { vehicle wheel }\end{array}$ & Revolute & 16 & 16 & $\begin{array}{l}\text { Axial } \\
\text { rotation }\end{array}$ \\
\hline $\begin{array}{l}\text { Upper structure and } \\
\text { turning platform }\end{array}$ & Revolute & 1 & 1 & $\begin{array}{l}\text { Axial } \\
\text { rotation }\end{array}$ \\
\hline $\begin{array}{l}\text { Upper structure and } \\
\text { skeleton }\end{array}$ & Revolute & 1 & 1 & $\begin{array}{l}\text { Axial } \\
\text { rotation }\end{array}$ \\
\hline $\begin{array}{l}\text { Upper structure and } \\
\text { clump weight }\end{array}$ & Fixed & 1 & 0 & Fixed \\
\hline $\begin{array}{l}\text { Upper structure and } \\
\text { cylinder barrel }\end{array}$ & Revolute & 1 & 1 & $\begin{array}{l}\text { Axial } \\
\text { rotation }\end{array}$ \\
\hline $\begin{array}{l}\text { Ground and guide } \\
\text { rail }\end{array}$ & Fixed & 2 & 0 & Fixed \\
\hline $\begin{array}{l}\text { Turning bearing } \\
\text { and turning } \\
\text { platform }\end{array}$ & Revolute & 1 & 1 & $\begin{array}{l}\text { Axial } \\
\text { rotation }\end{array}$ \\
\hline $\begin{array}{l}\text { Gate seat and } \\
\text { turning bearing }\end{array}$ & Fixed & 1 & 0 & Fixed \\
\hline $\begin{array}{l}\text { Cylinder barrel and } \\
\text { piston rod }\end{array}$ & $\begin{array}{l}\text { Translationa } \\
1\end{array}$ & 1 & 1 & Sliding \\
\hline $\begin{array}{l}\text { Turning platform } \\
\text { and piston cylinder }\end{array}$ & Revolute & 1 & 1 & $\begin{array}{l}\text { Axial } \\
\text { rotation }\end{array}$ \\
\hline $\begin{array}{l}\text { Arm frame and belt } \\
\text { conveyor }\end{array}$ & Fixed & 2 & 0 & Fixed \\
\hline $\begin{array}{l}\text { Arm frame and } \\
\text { bucket wheel }\end{array}$ & Fixed & 2 & 0 & Fixed \\
\hline
\end{tabular}

During the working process of bucket wheel stackerreclaimer, the turning platform, upper mechanism, and gate seat had small deformations [17], so that they can be modeled by using multiple rigid bodies. The pull rod of bucket wheel stacker-reclaimer belonged to a discrete flexible beam element, the pull rod structure was of the same shape as the beam cross-section, and the parts, such as driver's cage, belt conveyor, and bucket wheel were expressed by the properties of mass block. The established member models should have identical physical properties in the model operation [18]. The bushing flexible connection was set between the vehicle wheel and guide rail to ensure that the bearing reaction force of vehicle wheel in the established model was more realistic. The bushing connection is expressed as

$$
F_{j}=-F_{i}, T_{j}=-T_{i}-\delta F_{i}
$$

Where $T$ and $F$ denote the connection torque and connection acting force, respectively; $\delta$ refers to the instantaneous deformation vector at monitoring points $i$ and j.

The constraint relations between different components should be defined when the virtual prototype of bucket wheel stacker-reclaimer is established. In this study, the constraint relations between different components of bucket wheel stacker-reclaimer are listed in Table 1.

\subsection{Key parameter design of bucket wheel stacker- reclaimer}

The theoretical digging resistance of bucket wheel in the stacker-reclaimer is expressed as:

$P_{l}=f \times L$

Where $f$ and $L$ represent the unit digging resistance and the total length of cutting edge of bucket wheel, respectively. In the simulation analysis, the unit digging resistance of materials was $180 \mathrm{~N} / \mathrm{cm}$.

The total length of cutting edge at the bucket wheel part in the material digging process of bucket wheel stackerreclaimer is:

$L=2 m \sqrt{2 V_{0} \varphi / D} / \varphi$

Where $\varphi$ and $V_{0}$ represent the central angle of cutting process and the bucket capacity obtained through the theoretical calculation, respectively. $\phi=0.26 \pi \mathrm{rad}$ and $V_{0}=1.36 \mathrm{~m}^{3}$ are set; $m$ and $D$ denote the acting bucket count and diameter of bucket wheel, respectively, which are taken as 2 and $10 \mathrm{~m}$, respectively.

The average productivity of bucket wheel mechanism is theoretically calculated as:

$$
Q_{m}=\frac{V_{m}}{f} \rho n_{f}
$$

Where $f$ and $n_{f}$ represent the loosening coefficient and utilization factor, respectively, with value ranges of $[1.35,1.70]$ and $[0.65,0.93]$, respectively.

During the simulation process, the loosening coefficient and utilization factor were taken as 1.70 and 0.65 , respectively. $V_{m}$ and $\rho$ denote the volumetric productivity of bucket wheel mechanism and the material stacking density, respectively, and $V_{m}=61 z V_{0} n$.

$\beta R$ represents the lifting height needed to unload the materials; $\eta$ and $R$ represent the transmission efficiency of bucket wheel drive device and the radius of bucket wheel cut circle, respectively. The transmission efficiency of drive device in the bucket wheel stacker-reclaimer through the above parameter calculation is expressed as:

$$
W=\frac{P_{l} v}{1000 \eta}+\frac{Q_{m} \beta R g}{3600 \eta}
$$

where $\beta$ and $R$ are the lifting height coefficient and gravitational acceleration, respectively. The transmission efficiency and lifting height coefficient were set to 0.86 and 1.2 , respectively, and the radius of bucket wheel cut circle 
was set to $5 \mathrm{~m} . \mathrm{g}$ denotes the gravitational acceleration.

The operating torque $M_{\text {axis }}$ at the bucket wheel axle of bucket wheel drive device is expressed as:

$$
M_{\text {axis }}=9660 \mathrm{~W} / \mathrm{n}
$$

where $n$ is the rotational speed of bucket wheel.

In the discrete element simulation of virtual prototyping technology, the average productivity of bucket wheel mechanism is expressed as:

$$
Q_{m}^{\prime}=\frac{60 z n M}{1000}
$$

Where $M$ represents the single-bucket average material digging mass in the EDEM simulation, and $z$ denotes the bucket count.

The motor power of bucket wheel mechanism is expressed in the simulation model as follows:

$$
W^{\prime}=\frac{P_{L}^{\prime}}{1000 \eta}+\frac{P_{m}^{\prime} g h}{3600 \eta}
$$

where $P_{L}^{\prime}$ and $h$ represent the material lifting height and acting force borne by the bucket wheel body from the materials in the discrete element simulation process.

\subsection{EDEM discrete element simulation of the key parameters of bucket wheel stacker-reclaimer}

In accordance with the operating conditions of bucket wheel stacker-reclaimer, iron ore materials were set as the production materials, and their dimensions were set to $5 \mathrm{~m} \times 2.5 \mathrm{~m} \times 5 \mathrm{~m}$ in the discrete element simulation. In the operation process of bucket wheel stacker-reclaimer, only the influence of gravity on the particle material was considered. When the materials were naturally stacked, a slope angle was generated due to the gravity effect, which was approximate to the actual material stockpile [19]. After the material stockpile was generated, it was imported into the virtual prototype model of bucket wheel stackerreclaimer, and its material reclaiming process was simulated via EDEM software.

\section{Result Analysis and Discussion}

The virtual prototype model of bucket wheel stackerreclaimer was constructed on SIMSOLID software, as shown in Fig 1. The pull rod solution results of this virtual prototype model are displayed in Fig 2. The simulation results in Figs 1 and 2 show that the proposed method can be used to effectively establish the virtual prototype model of bucket wheel stacker-reclaimer. The pull rod of bucket wheel stacker-reclaimer belongs to a discrete flexible beam element. The proposed method can establish the rigid model and is effective for establishing the discrete flexible element model. A realistic 3D model was constructed in accordance with the actual operating state of bucket wheel stackerreclaimer. This model contributed to the accurate determination of the optimal parameters of bucket wheel stacker-reclaimer. It can be used to effectively simulate the pressure values of bucket wheel stacker-reclaimer and pull rod and provide the maximum and minimum pressure values.

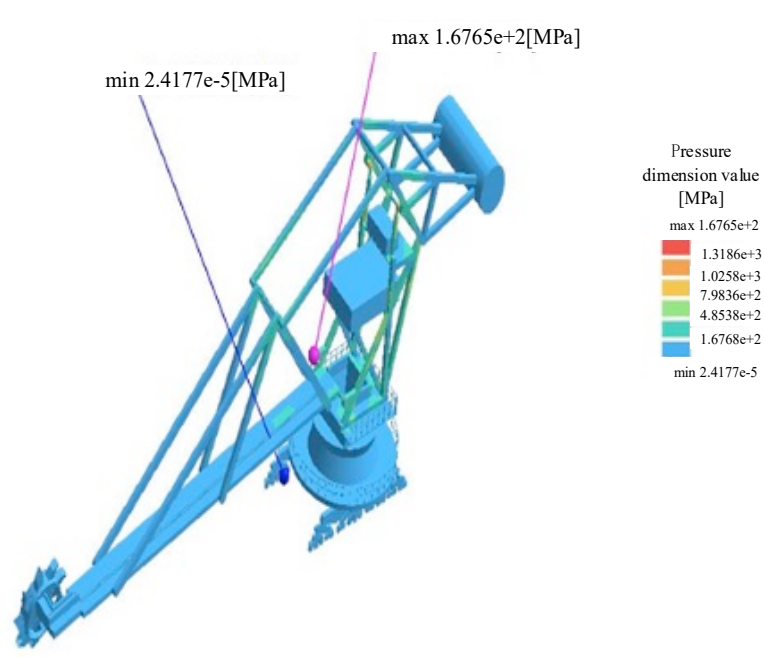

Fig.1. Bucket Wheel Stacker-Reclaimer Model

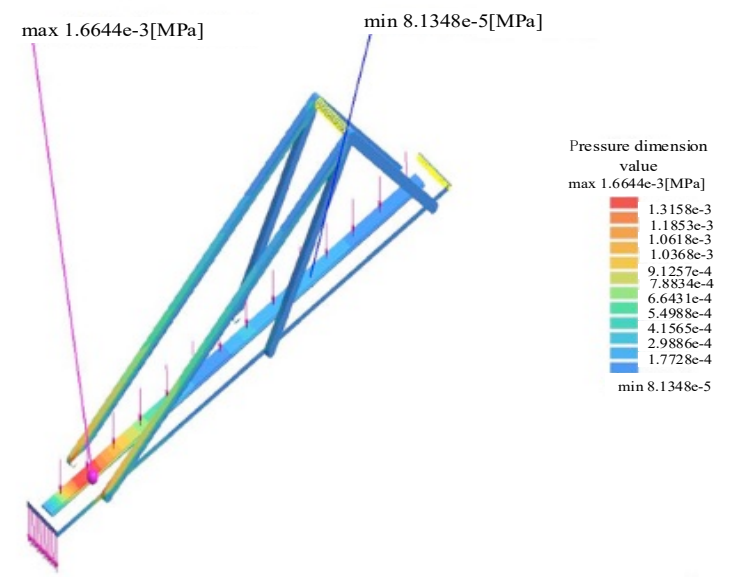

Fig.2. Pull Rod Simulation Resultsucket Wheel Stacker-Reclaimer Model

The material reclaiming process of bucket wheel stackerreclaimer was simulated by using the proposed model. The angular variation during this process is shown in Fig 3. The angular variation during the material reclaiming process was analyzed, as shown in Fig 3. A lifting angle of $128.87^{\circ}$ was found in the material reclaiming process simulated by the proposed method, and the angular variation was 24.95 in the material digging. The simulation results in Fig 3 show that the proposed method can simulate the material reclaiming process of bucket wheel stacker-reclaimer, indicating that this method can establish a virtual prototype model and realize the discrete element simulation through the established model.

When the bucket wheel stacker-reclaimer was operating under pitching conditions, the angular velocity curves of the upper structure within different ranges of pitch angle are shown in Fig 4. As shown in Fig 4, the initial pitch-up angular velocity and pitch-down angular velocity of the upper structure in the bucket wheel stacker-reclaimer are $0.028 \mathrm{rad} / \mathrm{s}$, They gradually tended to be steady through the angular velocity change for $20 \mathrm{~s}$, and the pitch angular velocity can be stabilized to $0.013 \mathrm{rad} / \mathrm{s}$. The pitch-up oscillation amplitude and frequency of bucket wheel stackerreclaimer are lower than those under the pitch-down condition by analyzing the angular velocity curves of the upper structure. Hence, the bucket wheel stacker-reclaimer is more flexible when it operated under the pitch-down 
condition, and the angular velocity change is more sensitive.

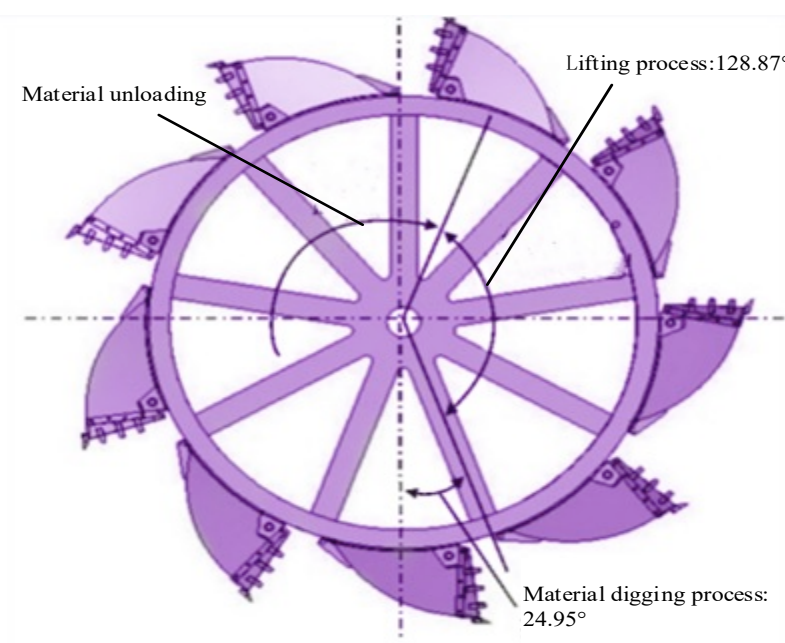

Fig. 3. Change of Angular Interval in the Material Reclaiming Process

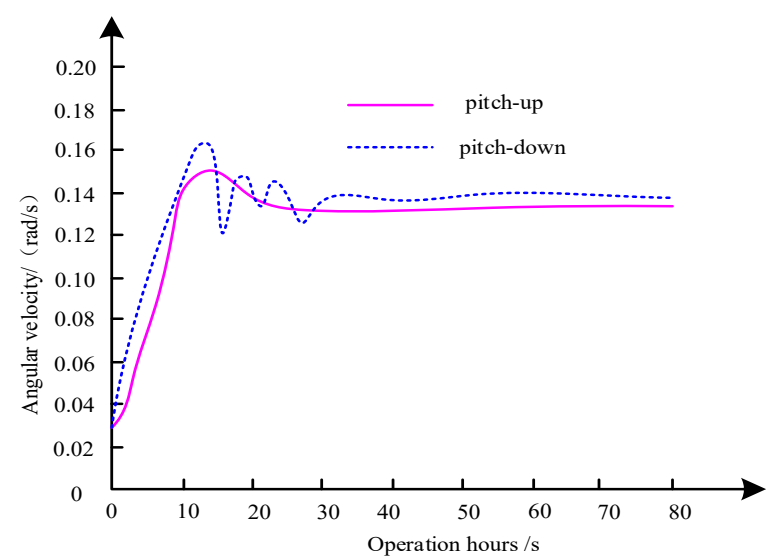

Fig. 4. Angular Velocity Curves of the Upper Structure

When the bucket wheel stacker-reclaimer operated under the turning condition, the pressure of No.8 vehicle wheel was measured by using a static measurement system. The load sensor in the static measurement system should be calibrated before the measurement. The sensor was placed on the jack, which was loaded at $600 \mathrm{~mm}$ away from the No.8 vehicle wheel, and the No.8 wheel of bucket wheel stacker-reclaimer broken away from the rail surface. The comparison results of wheel pressure in the virtual prototype model obtained through the discrete element simulation analysis are shown in Fig 5. The simulation results in Fig 5 show that when the complete bucket wheel stacker-reclaimer operated under turning conditions, the wheel pressure obtained through the discrete element simulation is extremely approximate to the experimental wheel pressure at different turning angles. The maximum relative error between the simulated wheel pressure and experimental result is lower than $1 \%$, indicating the high effectiveness of the established virtual prototype model of bucket wheel stacker-reclaimer. When applied to the established virtual prototype model, the discrete element simulation can realize the good simulation of the operating state of bucket wheel stacker-reclaimer.

The bucket count was 8 , and the rotational speed of bucket wheel was $9 \mathrm{r} / \mathrm{min}$ during the operation of bucket wheel stacker-reclaimer. The operating performance of bucket wheel stacker-reclaimer under different bucket volumes was calculated. When the bucket capacity was changed, the resistance variations in the operation of bucket wheel body in the stacker-reclaimer are displayed in Fig 6 . The average digging resistance, maximum digging resistance, and minimum digging resistance of bucket wheel stacker-reclaimer all increased with the bucket volume by analyzing the simulation results in Fig 6. From the simulation results in Fig 6, the digging resistance of bucket wheel stacker-reclaimer was in direct proportion to the bucket volume, and the digging resistance of bucket wheel stacker-reclaimer was enhanced with the increase in the bucket volume.

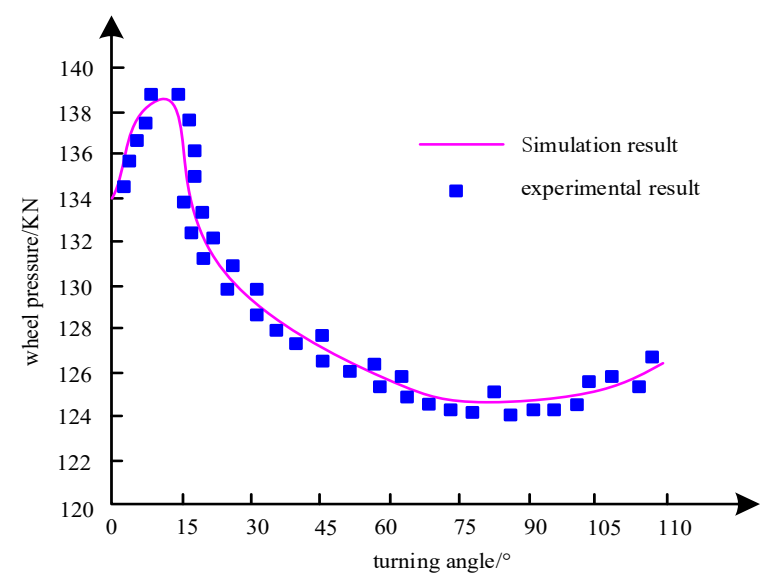

Fig. 5. Comparison Results of No.5 Wheel Pressure

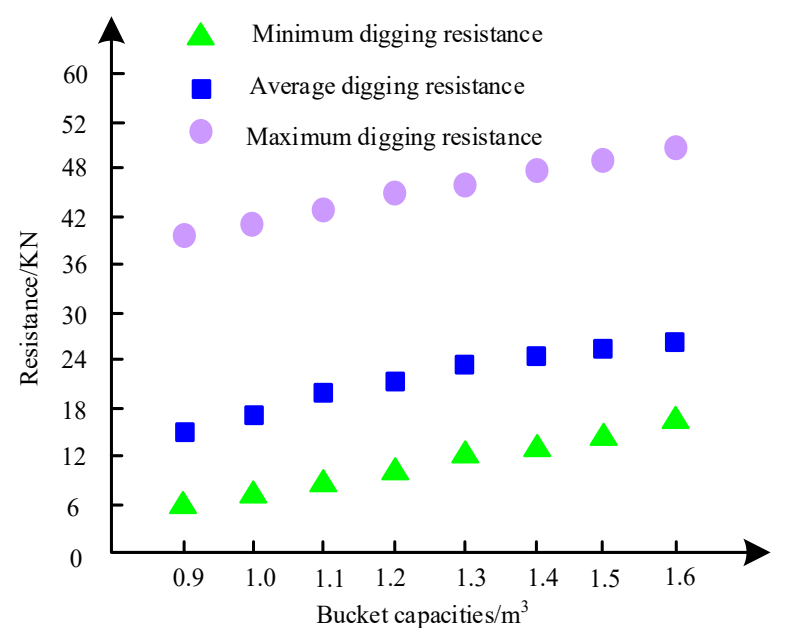

Fig. 6. Variation of Digging Resistance under Different Bucket capacities

Under the varying bucket capacity, the various results of actual loading capacity and maximum material digging volume are displayed in Fig 7. As shown in Fig 7, the material digging volume of machine was elevated with the increase in the bucket capacity. The increasing trend of actual loading capacity was highly similar to the maximum material digging volume. When the bucket capacity was increased to $1.6 \mathrm{~m}^{3}$, the maximum material digging volume was the maximum by analyzing the simulation results. However, the materials cannot be completely emptied under a small bucket capacity, and residual materials were found in the bucket when the gravity-type unloading mode was adopted by the bucket wheel stacker-reclaimer, thereby affecting the operating efficiency of bucket wheel stackerreclaimer. 


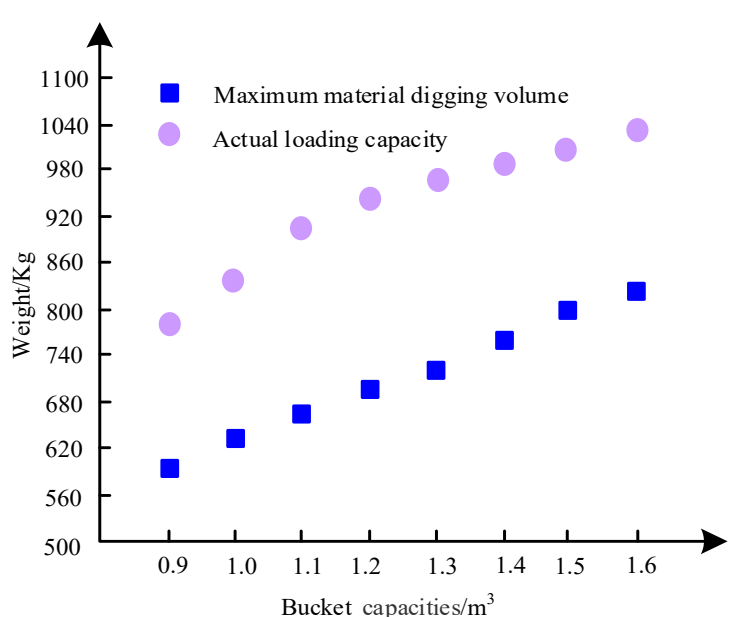

Fig. 7. Variation of Material Digging Volume under Different Bucket capacities

The influences of different bucket capacities on the operating performance of bucket wheel stacker-reclaimer were comprehensively analyzed, as shown in Fig 6 and 7. The digging resistance and loading capacity of bucket wheel stacker-reclaimer increased with the increase in the bucket capacity. When the bucket capacity was $1.6 \mathrm{~m}^{3}$, residual materials were found in the bucket, and the material loss rate was high, thereby reducing the productivity. Under the bucket capacity of $1.3 \mathrm{~m}^{3}$ and other parameters were unchanged, the bucket wheel stacker-reclaimer exhibited the highest productivity, and the operating performance was the best by comprehensively considering the digging resistance and loading capacity.

Under different rotational speeds of bucket wheel, the statistical results of the variation of force borne by the bucket under varying rotational angles of bucket wheel are presented in Fig 8. Under the fixed rotational speed, the resultant force borne by the bucket increased when the turning angle was enlarged by analyzing the simulation results in Fig 8. Under the same turning angle, the resultant force borne by the bucket increased somehow with the increase in rotational speed. When the bucket of bucket wheel stacker-reclaimer was under a large resultant force, the bucket wheel was subjected to a large impact vibration. Affected by the enormous resultant force, the wear of bucket wheel was serious, thereby increasing the operating energy consumption of bucket wheel stacker-reclaimer. From the simulation results in Fig 8, the rotational speed of bucket wheel influenced the digging resistance of bucket wheel stacker-reclaimer. Under a high rotational speed of bucket wheel, the digging resistance increased, and the digging resistance was greatly affected by the rotational speed of bucket wheel.

The mass variations of materials in the bucket under different rotational speeds and turning angles of bucket wheel are shown in Fig 9. As shown in Fig 9, the material mass in the bucket was influenced by the slight change in turning angle at different rotational speeds. At the same rotational speed, the material mass increased at a high rate with the increase in turning angle. When the turning angle was $50^{\circ}$, the increase in material mass reached the limit. With the continuous increase in the turning angle, the material mass reduced to some extent or remained unchanged at different rotational speeds. Under a fixed rotational speed, approximate material masses existed under different rotational speeds, and the variation amplitudes of single-bucket material digging volume and rotational speed were slightly the same. Therefore, the rotational speed had a minor effect on the material digging volume of bucket wheel mechanism. The rotational speed improved the production efficiency of bucket wheel stacker-reclaimer. However, the bucket wheel vibration was extremely large when the bucket wheel stacker-reclaimer operated at a high rotational speed. This condition exerted a more serious effect on the bucket wheel wear and increased the operating energy consumption of bucket wheel stacker-reclaimer. On this basis, selecting the rotational speed parameter under the operation of bucket wheel stacker-reclaimer is extremely important because the production efficiency of bucket wheel stacker-reclaimer can be improved only by selecting a proper rotational speed. The higher the rotational speed does not indicate the better the effect on improving the production efficiency.

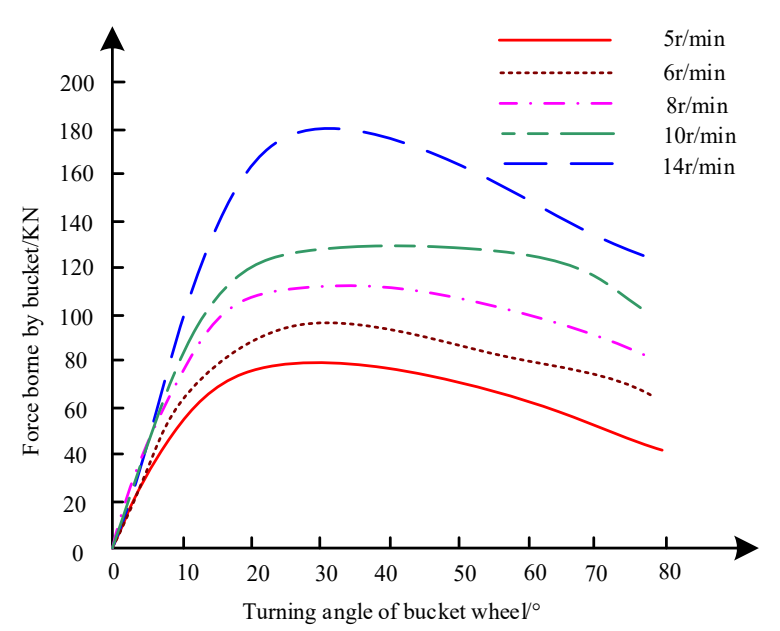

Fig. 8. Resultant Force Borne by the Bucket under Different Turning Angles of Bucket Wheel

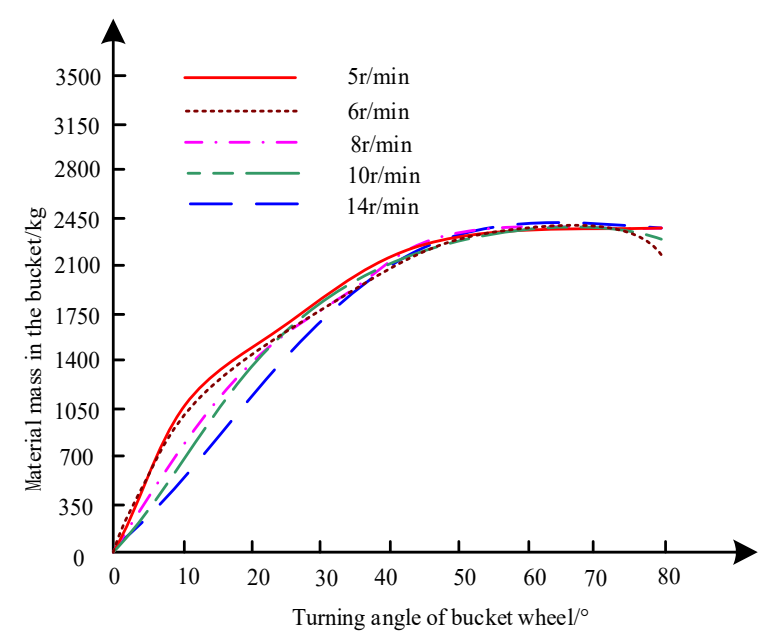

Fig. 9. Material Mass Change under Different Turning Angles

Under the varying rotational speed of bucket wheel, the quantitative description results of bucket wheel stackerreclaimer under the material unloading conditions are listed in Table 2.Affected by the rotational speed, the start angle and end angle of bucket wheel stacker-reclaimer increased with the elevation of rotational speed by analyzing the unloading conditions in Table 2. The start angle was influenced slightly by the rotational speed, and the end angle was affected considerably by the rotational speed. When the rotational speed was accelerated, the unloading interval range enlarged and resulted in the unloading delay under an 
extremely high rotational speed. When the materials were unloaded at a low rotational speed, the material stacking positions were more concentrated. When the rotational speed was elevated to $6 \mathrm{r} / \mathrm{min}$, the unloading interval was slightly dispersed compared with that at $5 \mathrm{r} / \mathrm{min}$. However, the unloaded materials were all concentrated in the designed unloading interval, and the maximum unloading volume was acquired. When the rotational speed was accelerated to 8 and $10 \mathrm{r} / \mathrm{min}$, the dispersity of material stacking was higher after the material unloading, and some materials were located outside the set unloading interval. When the rotational speed was elevated to $13 \mathrm{r} / \mathrm{min}$, the material unloading failed, and all materials were unloaded outside the unloading interval. In accordance with the above simulation results, the optimal rotational speed of bucket wheel stacker-reclaimer was 6 $\mathrm{r} / \mathrm{min}$.

Table. 2. Unloading Conditions at Different Rotational Speeds

\begin{tabular}{|c|c|c|c|c|c|}
\hline & $5 \mathrm{r} / \mathrm{min}$ & $6 \mathrm{r} / \mathrm{min}$ & $8 \mathrm{r} / \mathrm{min}$ & $10 \mathrm{r} / \mathrm{min}$ & $13 \mathrm{r} / \mathrm{min}$ \\
\hline Initial end $/^{\circ}$ & 125.68 & 126.85 & 127.84 & 129.52 & 132.57 \\
\hline End angle $/^{\circ}$ & 159.85 & 162.85 & 173.52 & 181.48 & \\
\hline $\begin{array}{l}\text { Unloading } \\
\text { time/s }\end{array}$ & 1.52 & 1.37 & 1.28 & 0.98 & \\
\hline $\begin{array}{l}\text { Unloading } \\
\text { angle }^{\circ}\end{array}$ & 34.85 & 38.64 & 41.85 & 43.85 & \\
\hline $\begin{array}{l}\text { Unloading } \\
\text { interval } / \mathrm{mm}\end{array}$ & 1385.64 & 1795.54 & 2785.15 & 3584.64 & \\
\hline
\end{tabular}

\section{Conclusion}

A virtual prototype model of bucket wheel stacker-reclaimer was established to determine its optimal parameters. The established virtual prototype model was highly effective on the basis of the simulation results. The conclusions were drawn as follows:

(1) The bucket wheel stacker-reclaimer can reach the optimal parameters for its good operation by determining the turning conditions and pitching conditions of the established virtual prototype. thereby providing a theoretical basis for improving the stability of complete machine and protecting it from being affected by the operation of bucket wheel stacker-reclaimer.

(2) The parameter changes in the material reclaiming and unloading processes of bucket wheel stacker-reclaimer are explored through the discrete element simulation, providing an idea for determining the working parameters of bucket wheel machine and optimizing its operation.

(3) The discrete element simulation results of bucket wheel stacker-reclaimer show that the machine can realize the optimal productivity under the bucket wheel rotational speed of $6 \mathrm{r} / \mathrm{min}$ and bucket capacity of $1.3 \mathrm{~m}^{3}$.

4) The discrete element simulation model can effectively avoid the waste of energy resources and reduce the energy in the operation of bucket wheel stacker-reclaimer with the best operating efficiency when it is used to determine the optimal parameters of bucket wheel stacker-reclaimer.

Although this study realizes the operation process simulation of bucket wheel stacker reclaimer, it verifies that the virtual prototype model of Bucket Wheel Stacker Reclaimer has high effectiveness. However, due to the limitations of level and time, the model is not verified by the simulation results of the prototype with similar power to the bucket wheel stacker reclaimer in the discrete element simulation. Therefore, in future research, more advanced discrete element three-dimensional simulation software can be used for verification, to improve the operation efficiency of bucket wheel stacker reclaimer and realize a good simulation of the operation state of bucket wheel stacker reclaimer.

This is an Open Access article distributed under the terms of the Creative Commons Attribution License.

\section{References}

1. Arsić, D., Gnjatović, N., Sedmak, S., Arsić, A., Uhričik, M., "Integrity Assessment and Determination of Residual Fatigue Life of Vital Parts of Bucket-Wheel Excavator Operating under Dynamic Loads". Engineering Failure Analysis, 105, 2019, pp.182195.

2. Peng, F., Wang, H. Y., Fang, F., Liu, Y. D., "Calibration of Discrete Element Model Parameters for Pellet Feed Based on Injected Section Method". Transactions of the Chinese Society for Agricultural Machinery, 49(4), 2018, pp. 140-147.

3. Yeom, S. B., Ha, E. S., Kim, M. S., Jeong, S. H., Hwang, S. J., Choi, D. H., "Application of the Discrete Element Method for Manufacturing Process Simulation in the Pharmaceutical Industry". Pharmaceutics, 11(8), 2019, pp. 414.

4. Ramírez-Gómez, Á., "The Discrete Element Method in Silo/Bin Research. Recent Advances and Future Trends". Particulate Science and Technology, 38(2), 2020, pp. 210-227.

5. Wu, D. P., Jin, J. B., Hua, Y. H., Wang, S., "Discrete Element Simulation and Parameter Analysis of Lateral Movement Process of Granular Layer". Chinese Journal of Applied Mechanics, 36(3), 2019, pp. 533-537.

6. Horabik, J., Wiącek, J., Parafiniuk, P., Stasiak, M., Bańda, M., Molenda, M. "Tensile Strength of Pressure-agglomerated Potato Starch Determined via Diametral Compression Test: Discrete Element Method Simulations and Experiments". Biosystems Engineering, 183, 2019, pp. 95-109.
7. Batista, J. N. M., Santos, D. A., Béttega, R., "Determination of the Physical and Interaction Properties of Sorghum Grains: Application to Computational Fluid Dynamics-Discrete Element Method Simulations of the Fluid Dynamics of a Conical Spouted Bed". Particuology, 54, 2021, pp. 91-101.

8. Clements, B., Pomalis, R., Zheng, L., Herage, T., Godin, E., "Method for Reducing Fuel Consumption and Greenhouse Gases in an Iron Ore Traveling Grate Furnace". Mining, Metallurgy \& Exploration, 29(3), 2012, pp. 137-143.

9. Araujo, L. S., De Almeida, L. H., Batista, E. M., Landesmann, A., "Failure of a Bucket-Wheel Stacker Reclaimer: Metallographic and Structural Analyses". Journal of Failure Analysis and Prevention, 12(4), 2012, pp. 402-407.

10. Liu, C. L., Wei, D., Song, J. N., Li, Y. N., Du, X., Zhang, F. Y., "Systematic Study on Boundary Parameters of Discrete Element Simulation of Granular Fertilizer". Sactions of the Chinese Society for Agricultural Machinery, 49(9), 2018, pp. 82-89.

11. Cao, B., Li, W. H., Wang, N., Bai, X. Y., Wang, C. W., "Calibration of Discrete Element Parameters of the Wet Barrel Finishing Abrasive Based on JKR Model". Surface Technology, 48(3), 2019, pp. 249-256.

12. Cheng, X., Li, C., Peng, Y., Zhao, C., "Discrete Element Simulation of Super-Ellipse Systems”. Granular Matter, 23, 2021, pp. 50 .

13. Vyazmensky, A., Stead, D., Elmo, D., Moss, A., "Numerical Analysis of Block Caving-Induced Instability in Large Open Pit Slopes: A Finite Element/Discrete Element Approach.” Rock Mechanics and Rock Engineering, 43(1), 2010, pp. 21-39. 
14. Sun, W., Peng, X., Wang, L., Dou, J., Geng, X., "Reliability-Based Weight Reduction Optimization of Forearm of Bucket-Wheel Stacker Reclaimer Considering Multiple Uncertainties". Structural and Multidisciplinary Optimization, 62(2), 2020, pp.2765-2782.

15. Billah, M., Farrell, J. A., "Calibration of Multi-LIDAR Systems: Application to Bucket Wheel Reclaimers". IEEE Transactions on Control Systems Technology, 6(28), 2020, pp. 2092-2103.

16. Kannan, A. S., Jareteg, K., Lassen, N. C. K., Carstensen, J. M., Hansen, M. A. E., Dam, F., Sasic, S., "Design and Performance Optimization of Gravity Tables using a Combined CFD-DEM Framework". Powder Technology, 318, 2017, pp. 423-440.
17. Tan, Y. Q., Xiao, X. W., Zhang, J. T., Jiang, S. Q., "Determination of Discrete Element Model Contact Parameters of Nylon Powder at SLS Preheating Temperature and its Flow Charateristics". Chinese Journal of Theoretical and Applied Mechanics, 51(1), 2019, pp. 5663.

18. Shi, L. R., Ma, Z. T., Zhao, W. Y., Yang, X. P., Sun B. G., Zhang, J. P., "Calibration of Simulation Parameters of Flaxed Seeds using Discrete Element Method and Verification of Seed-Metering Test". Transactions of the Chinese Society of Agricultural Engineering, 35(20), 2019, pp. 25-33.

19. Yang, J., Ma, C.H., Cheng, L., Ran, L., Huang Z. H., "Mesoscopic Parameter Calibration Model of Discrete Elements in Rockfill Material Based on QGA-SVM". Advances in Science and Technology of Water Resources, 38(5), 2018, pp. 53-58. 